Corrigendum

\title{
In the Shadow of Celebrity? World-Class University Policies and Public Value in Higher Education
}

Leon Cremonini, Don F. Westerheijden, Paul Benneworth and Hugh Dauncey

Higher Education Policy (2014) 27, 429. doi:10.1057/hep.2014.16;

published online 10 June 2014

Correction to: Higher Education Policy advance online publication 15 October 2013. doi: 10.1057/hep.2013.33

The authors of this article would like to clarify the fact that the definitions of the five variables for Figure 1 were taken from the same source as the model featured in the article: Cremonini, L., Benneworth, P., Westerheijden, D.F. and Dauncey, H. (2013) 'Reconciling Republican "Egalité" and Global Excellence Values in French Higher Education' in J.C. Shin and B.M. Kehm (eds.) Institutionalization of WorldClass University in Global Competition, Dordrecht: Springer.

The definitions are a direct quotation of text on page 104 of that source and should have been indicated as such.

The authors would like to apologise for any confusion caused. 